\title{
Formation and Regeneration of Protoplasts from Conidiobolus lamprauges
}

\author{
By FUMIYASU ISHIKAWA† AND KUNIO OISHI* \\ Institute of Applied Microbiology, University of Tokyo, 1-1-1 Yayoi, Bunkyo-ku, Tokyo 113, \\ Japan
}

(Received 5 June 1985; revised 12 August 1985)

\begin{abstract}
Protoplasts were formed from aged germlings and mycelia of Conidiobolus lamprauges, using a combination of chitinase and $\beta$-glucanase. Methanol, ethanol and propanol stimulated protoplast formation, apparently by a mechanism different from that of mercaptoethanol. Regeneration of protoplasts in soft agar was detectable by light microscopy $2 \mathrm{~h}$ after incubation and colonies were observable by the naked eye within $40 \mathrm{~h}$; the regeneration rate was $65 \%$.
\end{abstract}

\section{INTRODUCTION}

Chitin is widely distributed in invertebrates, fungi and yeasts but is not found in vertebrates (Muzzarelli, 1977). To date, chitin synthesis by 'chitosomes' (Glaser \& Brown, 1957; RuizHerrera et al., 1977; Bartnicki-Garcia et al., 1979) has been investigated. Chitin synthase (EC 2.4.1.16) has not yet been obtained in a highly purified state and its detailed enzymic properties remain unclear. Lipid-linked reactions may be involved. Yeasts possess dolichyl-bound saccharides as intermediates in glycoprotein synthesis (Bretthauer \& $\mathrm{Wu}, 1975$ ), and involvement of lipid-linked reactions in the initiation of chitin synthesis in crustacea was suggested by Horst (1983). Katoh et al. (1976) found that conidia of Penicillium citrinum could not germinate but grew abnormally into multinuclear giant cells in the presence of sublethal concentrations of tunicamycin, an antibiotic that inhibits the biosynthesis of chitin in insects (Quesada-Allue, 1982).

We have selected the fungus Conidiobolus lamprauges for the study of chitin synthesis. It has the following desirable characteristics: (i) it contains chitin in the cell wall; (ii) sufficient growth (and synthesis of chitin) occurs in an appropriate medium; (iii) the cell walls can be removed easily to form piotoplasts; and (iv) vegetative cells can be regenerated from protoplasts at a high frequency and a high rate. In this paper we describe the formation and regeneration of protoplasts from $C$. lamprauges.

\section{METHODS}

Organism. Conidiobolus lamprauges Drechsler no. 454 (=ATCC 46830), isolated from soil (Ishikawa et al., 1979) and maintained in our laboratory, was used throughout the present work.

Culture conditions. The organism was grown at $27^{\circ} \mathrm{C}$ on solidified $\mathrm{ME}$ medium held in place on the cover of large Petri dishes by a small frame (Fig. 1). ME medium consists of $2 \%(w / v)$ Bacto Malt Extract (Difco), $0 \cdot 1 \%(w / v)$ Polypepton (Daigo Eiyokagaku Co., Osaka, Japan), $2 \%(\mathrm{w} / \mathrm{v})$ glucose and $2 \%(\mathrm{w} / \mathrm{v})$ agar (Nakarai Chemicals, Kyoto, Japan) in deionized water. When conidia were fully matured, they dropped from the mycelial mats and fell into the $0.05 \%(\mathrm{w} / \mathrm{v}) 2$-deoxyglucose solution in the dishes. This solution inhibited germination and further growth of the conidia, and kept them at a uniform phase of growth. The conidia thus obtained were washed three times with $0.05 \mathrm{M}$-sodium phosphate buffer (PB, pH 7.0), and cultured at $27^{\circ} \mathrm{C}$ in MY medium, which is composed of $0.3 \%(\mathrm{w} / \mathrm{v})$ Bacto Malt Extract (Difco), $0.3 \%(\mathrm{w} / \mathrm{v})$ Bacto Yeast Extract (Difco), $0.5 \%(\mathrm{w} / \mathrm{v})$ Polypepton (Daigo) and $1 \%(\mathrm{w} / \mathrm{v})$ lactose in $0.05 \mathrm{M}-\mathrm{PB}(\mathrm{pH} 7 \cdot 0)$. At appropriate intervals, mycelia were harvested and examined for their convertibility to protoplasts.

$\dagger$ Present address: Yakult Central Institute for Microbiological Research, 1796 Yaho, Kunitachi City, Tokyo 186, Japan. 
(a)
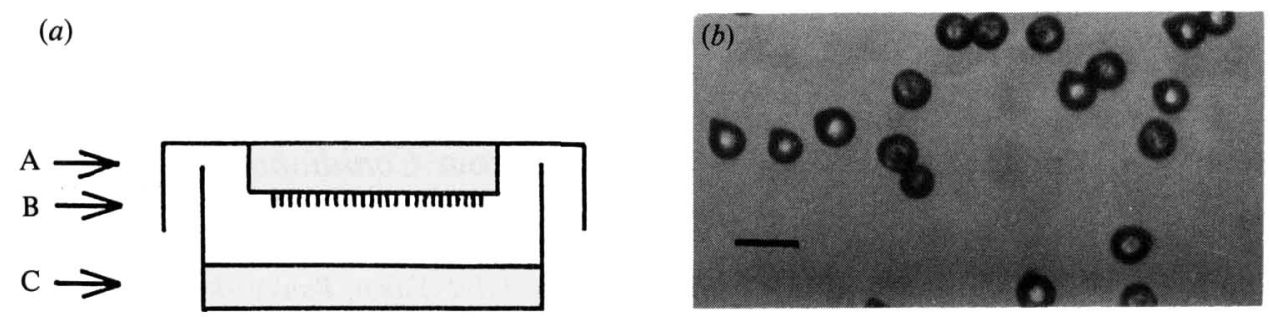

Fig. 1. Synchronous preparation of Conidiobolus lamprauges conidia. (a) Culture dish used for conidia trapping: A, ME medium; B, mat of $C$. lamprauges; $C$, trapping solution $(0.05 \% 2$-deoxyglucose). (b) Conidia trapped in trapping solution. Bar, $25 \mu \mathrm{m}$.

Formation of protoplasts. The standard reaction mixture comprised $20 \mu \mathrm{l}$ of an aqueous solution containing $0.4 \mathrm{mg}$ Arthrobacter luteus Zymolyase 60000 (Seikagaku Kogyo Co.), $40 \mu \mathrm{l}$ Streptomyces griseus chitinase solution (Sigma; lyophilized crude powder $0.8 \mathrm{mg}$ ), $120 \mu \mathrm{l} 0.05 \mathrm{M}-\mathrm{PB}$ (pH 7.0), $20 \mu 110 \mathrm{M}$-ethanol or $5 \mathrm{M}-2$-mercaptoethanol, $200 \mu \mathrm{l} 2.5 \mathrm{M}$-D-sorbitol in $0.05 \mathrm{M}-\mathrm{PB}$ ( $\mathrm{pH} \mathrm{7.0)}$ ), and $600 \mu \mathrm{l}$ washed mycelial suspension $(1 \%$, v/v, packed mycelium in $0 \cdot 05 \mathrm{M}-\mathrm{PB}, \mathrm{pH} 7 \cdot 0$ ). In some experiments, $40 \mu$ l Helix pomatia sulphatase solution (Sigma, type $\mathrm{H}-2$ ) was also added. The reaction mixture was filter-sterilized (Millipore filter, pore size $0.45 \mu \mathrm{m}$ ) when the protoplasts were to be prepared aseptically. Enzyme digestion was carried out at $30^{\circ} \mathrm{C}$ for 2 to $3 \mathrm{~h}$ with gentle shaking. After the reaction, the remaining mycelium and cell debris were removed by low-speed centrifugation. The protoplasts formed were washed three times with $0.05 \mathrm{M}-\mathrm{D}$-sorbitol $/ 0.05 \mathrm{M}-\mathrm{PB}$ solution ( $\mathrm{pH} 7 \cdot 0$ ). Protoplast formation was determined by phase-contrast microscopy and by rupture of the protoplasts by dilution. Numbers of protoplasts were counted with a Neubauer-type haematocytometer; the variation was no more than $0 \cdot 1 \times 10^{6}$ protoplasts $\mathrm{ml}^{-1}$ among five experiments.

Regeneration of protoplasts. One hundred protoplasts were aseptically added to $5 \mathrm{ml} \mathrm{ME}$ medium containing $0.5 \%$ agar and $0.5 \mathrm{M}$-D-sorbitol, overlaid on ME medium supplemented with $2 \%(\mathrm{w} / \mathrm{v})$ agar and $0.5 \mathrm{M}$-D-sorbitol in $9 \mathrm{~cm}$ Petri dishes, and incubated at $27^{\circ} \mathrm{C}$. Samples were withdrawn at intervals and regeneration was observed by phase-contrast microscopy.

\section{RESULTS}

\section{Enzymes required for protoplast formation}

The major polysaccharide components of the cell wall of Conidiobolus lamprauges are chitin, $\beta$ glucan and an unidentified mannosyl saccharide (Ishikawa et al., 1983). Commercial preparations of chitinase, Zymolyase ( $\beta$-glucanase) and sulphatase (mostly $\beta$-glucuronidase) were examined for their ability to induce protoplast formation (Fig. 2). Individually they did not release protoplasts. Chitinase and sulphatase combined were also ineffective, but Zymolyase plus sulphatase showed a slight activity. When Zymolyase and chitinase were used in combination, almost all the mycelia were converted to protoplasts within $2 \mathrm{~h}$, giving a density of about $2 \times 10^{6}$ protoplasts $\mathrm{ml}^{-1}$. Prolonged incubation resulted in a decrease of protoplast numbers, due to protoplast lysis. Addition of sulphatase to the mixture of Zymolyase and chitinase increased the rate of protoplast formation only slightly.

\section{Enhancers of protoplast formation}

Hardly any protoplasts were obtained from C. lamprauges by incubation with Zymolyase and chitinase in the absence of mercaptoethanol. Table 1 shows the effect on protoplast formation of several reducing agents, including mercaptoethanol, and of lower alcohols as analogues of mercaptoethanol. Sodium sulphide enhanced protoplast formation, while dithiothreitol and Lascorbic acid showed weak and no activity, respectively. Lower alcohols were generally as stimulatory as mercaptoethanol. To determine whether mercaptoethanol and lower alcohols acted on the lytic enzymes or on the cells of $C$. lamprauges, these compounds were added to the reaction mixture prior to the addition of the enzymes, incubated at $30^{\circ} \mathrm{C}$ for $2 \mathrm{~h}$, and washed off (Table 2). Preincubation of the cells with mercaptoethanol gave no stimulatory effect, whereas ethanol stimulated subsequent cell wall lysis by the enzymes. Preincubation of the cells in 


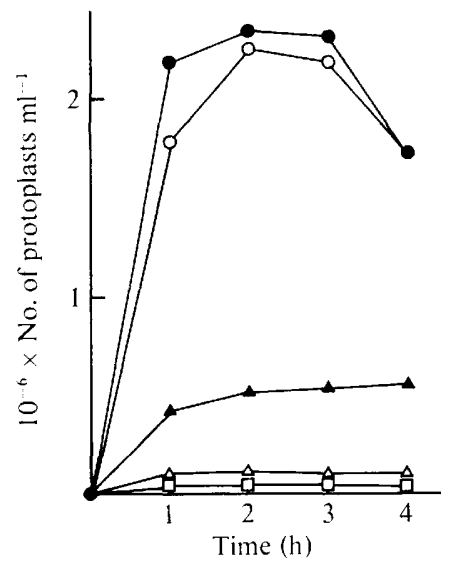

Fig. 2. Effect of lytic enzymes on protoplast formation. Mycelia were treated with Zymolyase plus chitinase plus sulphatase ( ), with Zymolyase plus chitinase (O), with Zymolyase plus sulphatase (A), with chitinase plus sulphatase $(\triangle)$, or without enzymes $(\square)$. Ethanol $(200 \mathrm{mM})$ was added to all reaction mixtures. The results are from a typical experiment.

Table 1. Effect of reducing agents and lower alcohols on protoplast formation

$\begin{array}{ccc}\text { Concn } & 10^{-6} \times \text { No. of } \\ \text { Addition } & (\mathrm{mM}) & \text { protoplasts } \mathrm{ml}^{-1}\end{array}$

$\begin{array}{lcc}\text { Deionized water } & - & 0 \cdot 12 \\ \text { 2-Mercaptoethanol } & 100 & 1.51 \\ \text { Dithiothreitol } & 100 & 0.66 \\ \text { L-Ascorbic acid } & 100 & 0 \cdot 12 \\ \text { Sodium sulphide } & 100 & 1.86 \\ \text { Methanol } & 200 & 1.44 \\ \text { Ethanol } & 200 & 1.62 \\ \text { Propanol } & 200 & 1.55\end{array}$

Table 2. Effect on protoplast formation of treatment of mycelia with mercaptoethanol and ethanol prior to enzyme digestion

\begin{tabular}{|c|c|c|}
\hline \multicolumn{2}{|c|}{ Addition during: } & \multirow{2}{*}{$\begin{array}{l}10^{-6} \times \text { No. of } \\
\text { protoplasts } \mathrm{ml}^{-1}\end{array}$} \\
\hline Preincubation & Incubation & \\
\hline - & Deionized water & $0 \cdot 21$ \\
\hline & 2-Mercaptoethanol (100 mM) & $1 \cdot 60$ \\
\hline & Ethanol $(200 \mathrm{~mm})$ & $1 \cdot 53$ \\
\hline Deionized water & - & 0.94 \\
\hline 2-Mercaptoethanol $(100 \mathrm{~mm})$ & - & 0.91 \\
\hline Ethanol $(200 \mathrm{mM})$ & $\ldots$ & $1 \cdot 35$ \\
\hline
\end{tabular}

deionized water without ethanol also considerably enhanced cell wall lysis. The optimal concentrations of mercaptoethanol and ethanol were $100 \mathrm{~mm}$ and $200 \mathrm{~mm}$, respectively; higher concentrations decreased protoplast yields, due to protoplast lysis.

D-Sorbitol $(0.5$ to $0.7 \mathrm{M})$ was the best osmotic stabilizer for protoplast formation. A pH value of 7.0, which is optimal for Zymolyase activity, was most favourable for the formation of protoplasts.

\section{Effect of mycelial age on protoplast formation}

Newly isolated conidia and young germlings of $C$. lamprauges were resistant to the lytic enzymes and did not release protoplasts. However, germlings with empty conidial shells and $20 \mathrm{~h}$ cultured mycelia were susceptible to the enzymes and were completely converted to protoplasts. 

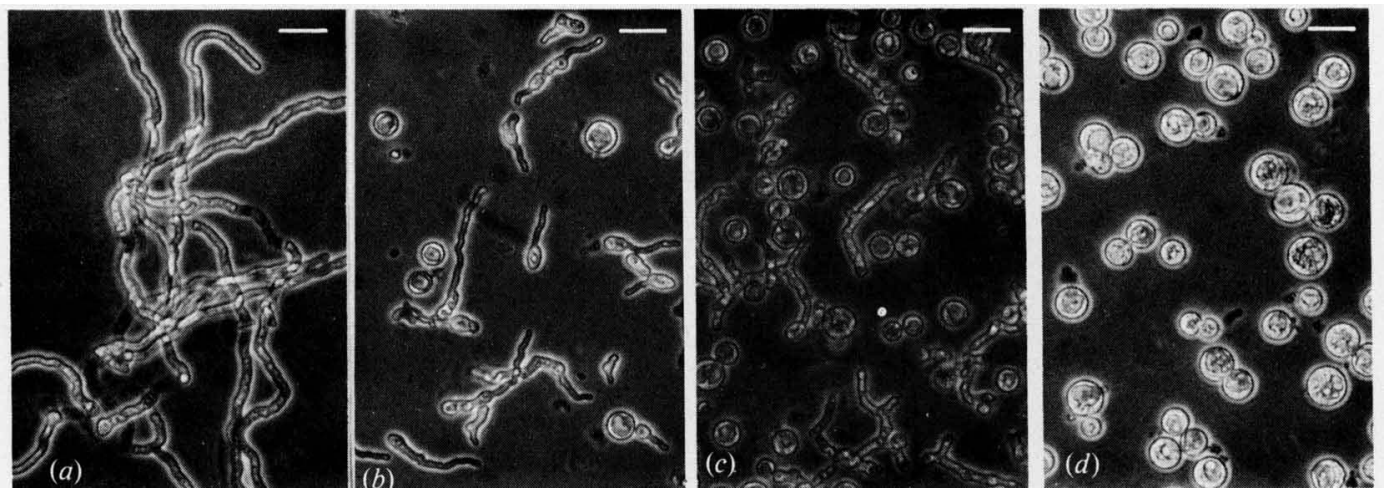

Fig. 3. Time course of protoplast formation in the standard reaction mixture. Micrographs after $0 \mathrm{~min}$ $(a), 30 \mathrm{~min}(b), 60 \mathrm{~min}(c)$ and $120 \mathrm{~min}(d)$ incubation. Bars, $25 \mu \mathrm{m}$.
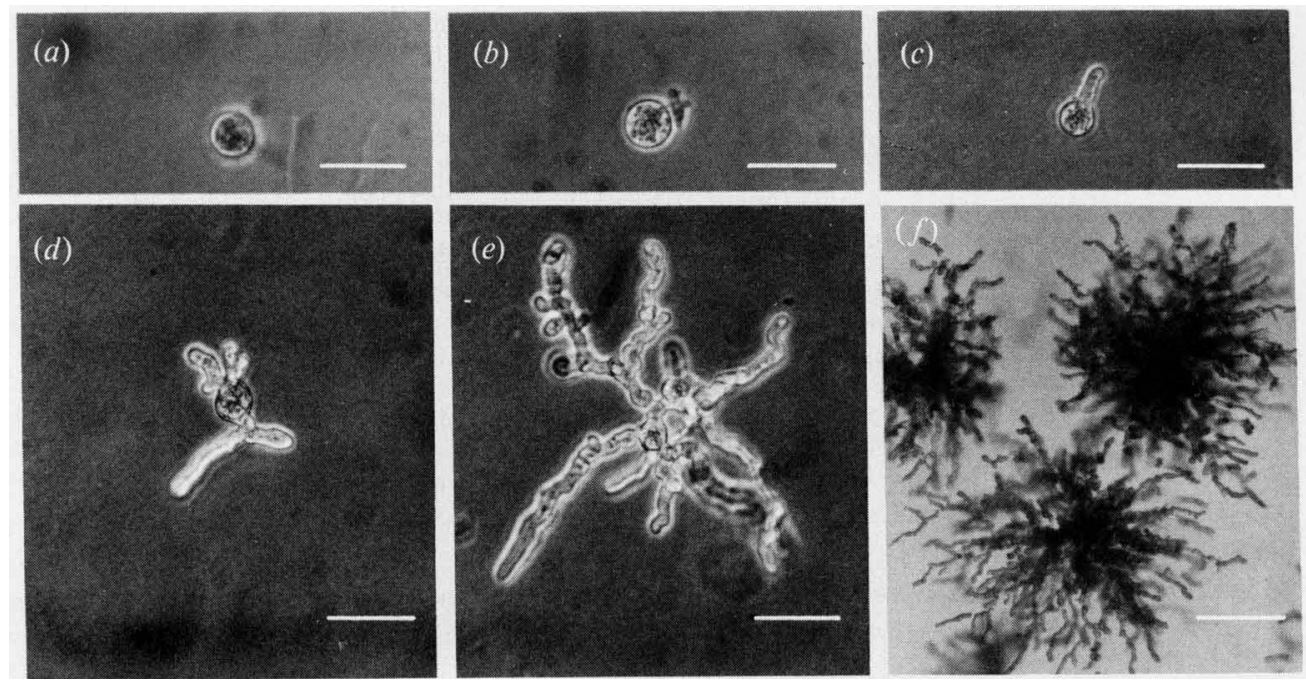

Fig. 4. Time course of protoplast regeneration in soft ME agar medium. Micrographs after $0 \mathrm{~h}(a), 2 \mathrm{~h}$ $(b), 4 \mathrm{~h}(c), 8 \mathrm{~h}(d), 20 \mathrm{~h}(e)$ and $40 \mathrm{~h}(f)$ incubation. Bars in $(a-e), 25 \mu \mathrm{m}$; bar in $(f), 50 \mu \mathrm{m}$.

\section{Microscopic observation of protoplast formation}

The time course of protoplast formation was observed microscopically under optimal conditions, i.e. with mycelia cultured for $20 \mathrm{~h}$ treated with a combination of Zymolyase 60000 and chitinase in the presence of $200 \mathrm{~mm}$-ethanol. The mycelia were subdivided into small irregular fragments within $30 \mathrm{~min}$ of the start of incubation (Fig. 3). The fragments were transformed into distorted cells within a further $30 \mathrm{~min}$, and after $2 \mathrm{~h}$ incubation almost all the cells were converted to spherical and osmotically labile protoplasts 7.5 to $20 \mu \mathrm{m}$ in diameter.

\section{Regeneration of protoplasts}

The protoplasts obtained readily regenerated hyphae when cultured in soft agar or in liquid media. The time course of regeneration in a soft ME agar is shown in Fig. 4. Morphological changes were detected as early as $2 \mathrm{~h}$, when the surface of the protoplasts became irregularly shaped. Hyphal growth appeared clearly after $4 \mathrm{~h}$ and many extended hyphae and branchings were observed after $8 \mathrm{~h}$. No budding and protrusion occurred in the soft ME agar. After $40 \mathrm{~h}$ incubation single protoplasts had developed into colonies which could be observed with the naked eye. The efficiency of regeneration was approximately $65 \%$ in this system, and was the same in soft MY agar and in liquid ME and MY media. 


\section{DISCUSSION}

Protoplasts are useful for studies on cell wall biosynthesis and on the secretion process of extracellular and cell wall-bound enzymes, and for fusion in somatic cell genetics (Villanueva, 1966). We have studied exocellular and endocellular chitin-binding lectins of $C$. lamprauges (Ishikawa et al., 1979, 1983). This fungus belongs to the Entomophthorales, which includes a number of insect pathogens (King, 1976). It contains chitin in the cell wall and produces exocellular chitinase and $\beta$ - $N$-acetylglucosaminidase (Ishikawa et al., 1981). Thus $C$. lamprauges is a good system for studying the mechanism of biosynthesis and biodegradation of chitin in fungi in relation to the physiological functions of chitin-binding lectins, chitinase, and $\beta-N$ acetylglucosaminidase. Since $C$. lamprauges formed protoplasts readily and regenerated hyphae at a high frequency and a high rate, we are attempting to use this organism to investigate the 'primer' which may be necessary for regeneration of chitin in the cell wall (Peberdy, 1979) and to screen new inhibitors of chitin biosynthesis in fungi.

Protoplasts were formed from older germlings and mycelia of $C$. lamprauges by treatment with $Z$ ymolyase ( $\beta$-glucanase) and chitinase. Mannase was not required for protoplast formation, though mannose constitutes one-third of the sugars in the cell wall of this organism. Snail sulphatase is a potent enzyme for the lysis of yeast and fungal cell walls (Eddy, 1958, Ohnuki et al., 1981); it released protoplasts from the conidia of Neurospora crassa, which are more resistant than vegetative forms (Bachmann \& Bonner, 1959). In the present study, however, this enzyme was ineffective when used alone and was unnecessary in the presence of Zymolyase and chitinase.

Mercaptoethanol was required for the action of Zymolyase on living cells of Candida lipolytica; cysteine, sodium thioglycollate and sodium sulphide enhanced lysis to a lesser extent, whereas dithiothreitol, L-ascorbic acid and cysteamine were ineffective (Kaneko et al., 1973). When young mycelia of Geotrichum candidum were treated with mercaptoethanol prior to the digestion by a lytic enzyme complex of Streptomyces satsumaensis, cell wall lysis was markedly accelerated (Dooijewaard-Kloosterziel et al., 1973). The former but not the latter was also observed in the present study.

It is not clear whether the effect of lower alcohols was derived from their structural resemblance to mercaptoethanol. Treatment of $C$. lamprauges cells with those alcohols prior to enzyme digestion resulted in enhanced protoplast formation, but mercaptoethanol did not have this effect, suggesting that the mechanism of action of the alcohols was not identical to that of mercaptoethanol. It is possible that an autolytic reaction or selective inhibition of cell wall synthesis which is accelerated by the alcohols may participate in protoplast formation. Protoplast formation without added enzyme was reported in an osmotic mutant of $N$. crassa (Hamilton \& Calvet, 1964).

High concentration of sugars may affect synthesis and autolysis of cell walls (Hamilton \& Calvet, 1964; de Terra \& Tatum, 1961). In the present study, however, because the protoplasts regenerated hyphae effectively in the presence of 0.5 to $0.7 \mathrm{M}$-D-sorbitol it presumably acted solely as an osmotic stabilizer.

We thank Dr K. Kitamura of Applied Bioscience Laboratory, Kirin Brewery Co. Ltd for his special advice on the properties of Zymolyase 60000 . This work was supported in part by a grant from the Foundation for the Promotion of Research on Medical Resources, Tokyo.

\section{REFERENCES}

Bachmann, B. J. \& Bonner, D. M. (1959). Protoplasts from Neurospora crassa. Journal of Bacteriology 78, $550-556$.

Bartnicki-Garcia, S., Ruiz-Herrera, J. \& Bracker, C. E. (1979). Chitosomes and chitin synthesis. In Fungal Walls and Hyphal Growth, pp. 150-168. Edited by J. H. Burnett \& A. P. J. Trinci. Cambridge: Cambridge University Press.

Bretthauer, R. K. \& WU, S. (1975). Synthesis of the mannosyl- $O$-serine (threonine) linkage of glycoproteins from polyisoprenylphosphate mannose in yeast (Hansenula holstii). Archives of Biochemistry and Biophysics 167, 151-160.

DooiJewaARd-Kloosterziel, A. M. P., Sietsma, J. H. \& Wouters, J. T. M. (1973). Formation and regeneration of Geotrichum candidum protoplasts. Journal of General Microbiology 74, 205-209.

EDDY, A. A. (1958). The structure of the yeast cell wall. 
II. Degradative studies with enzymes. Proceedings of the Royal Society B149, 425-440.

Glaser, L. \& BRown, D. H. (1957). Synthesis of chitin in cell-free extracts of Neurospora crassa. Journal of Biological Chemistry 228, 729-742.

Hamilton, J. G. \& Calvet, J. (1964). Production of protoplasts in an osmotic mutant of Neurospora crassa without added enzyme. Journal of Bacteriology 88, 1084-1086.

Horst, M. N. (1983). The biosynthesis of crustacean chitin. Isolation and characterization of polyprenollinked intermediates from brine shrimp microsomes. Archives of Biochemistry and Biophysics 223, 254-263.

IsHIKAWA, F., OISHI, K. \& AIDA, K. (1979). Chitinbinding hemagglutinin produced by Conidiobolus lamprauges. Applied and Environmental Microbiology 37, $1110-1112$.

IsHikaWA, F., OISHI, K. \& AIDA, K. (1981). Chitinase production by Conidiobolus lamprauges and other Conidiobolus species. Agricultural and Biological Chemistry 45, 2361-2362.

IsHIKAwA, F., OISHI, K. \& AIDA, K. (1983), Chitinbinding hemagglutinin associated with cell wall of Conidiobolus lamprauges. Agricultural and Biological Chemistry 47, 587-592.

Kaneko, T., Kitamura, K. \& Yamamoto, Y. (1973). Susceptibilities of yeasts to yeast cell wall lytic enzyme of Arthrobacter luteus. Agricultural and Biological Chemistry 37, 2295-2302.

Katoh, Y., Kuninaka, A., Yoshino, H., Takatsuki,
A., Yamasaki, M. \& TAMURa, G. (1976). Formation of fungal multinuclear giant cells by tunicamycin. Journal of General and Applied Microbiology 22, 247258.

KING, D. S. (1976). Systematics of Conidiobolus (Entomophthorales) using numerical taxonomy. I. Biology and cluster analysis. Canadian Journal of Botany 54, 45-65.

Muzzarelli, R. A. A. (1977). Chitin. Oxford: Pergamon Press.

OHNUKı, T., ITOH, Y. \& BEPPU, T. (1981). Intraspecific and interspecific hybridization of Mucor pusillus and M. miehei by protoplast fusion. Agricultural and Biological Chemistry 46, 451-458.

PEBerdy, J. F. (1979). Wall biogenesis by protoplasts. In Fungal Walls and Hyphal Growth, pp. 49-70. Edited by J. H. Burnett \& A. P. J. Trinci. Cambridge: Cambridge University Press.

Quesada-Allue, L. A. (1982). The inhibition of insect chitin synthesis by tunicamycin. Biochemical and Biophysical Research Communications 105, 312-319.

Ruiz-Herrera, J., Lopez-Romero, E. \& BARTNickIGARCIA, S. (1977). Properties of chitin synthetase in isolated chitosomes from yeast cells of Mucor rouxii. Journal of Biological Chemistry 252, 3338-3343.

DE TERRA, N. \& TATUM, E. L. (1961). Colonial growth of Neurospora. Science 134, 1066-1068.

Villanueva, J. R. (1966). Protoplasts of fungi. In The Fungi, vol. 2, pp. 3-62. Edited by G. C. Ainsworth \& A. S. Sussman. New York: Academic Press. 